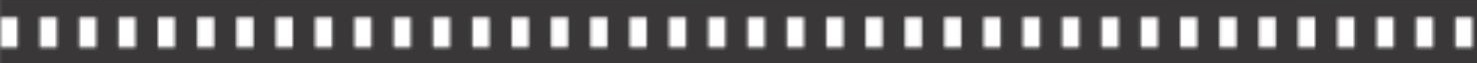 Origen del paradigma de la fotografía publicitaria moderna: el Tenedor de André Kertesz 0 el Cuello Idestyle de Paul Outerbridge |
}

José Manuel Susperregui 


\title{
Origen del paradigma de la fotografía publicitaria moderna: el Tenedor de André Kertesz 0 el Cuello Idestyle de Paul Outerbridge
}

The paradigm's origin in the modern publicitary photography: the Tenedor of André Kertesz or the Cuello Idestyle of Paul Outerbridge

José Manuel Susperregui*

\begin{abstract}
Resumen: Debido a la ambigüedad sobre los origenes de la fotografía publicitaria y su paradigma este artículo se ha centrado en dos imágenes antológicas, como son el Tenedor de Kertész y el Cuello Idestyle de Outerbridge. A través del análisis de estas imágenes y sus autores se llega a la conclusión de que la fotografía de Outerbridge, el Cuello Idestyle, es más paradigmática porque contiene la información suficiente y necesaria para que el receptor pueda identificar perfectamente el producto que se anuncia, superando al Tenedor de Kertész en este nivel de información.
\end{abstract}

Palabras-clave: Fotografia; publicidad; Kertesz; Outerbridge.

\begin{abstract}
Due to the ambiguity of the origins of advertising photography and its paradigm this article has been focussed on two anthological images : the Kertesz Fork and Outerbridge's Idestyle Neck. The analysis of these images and their authors has enabled us to conclude that Outerbridge's photography the Idestyle Neck is more paradigmatic as it conveys sufficient and necessary information to enable the receiver to perfectly identify the product being advertised, surpassing the Kertesz Fork at this information level.
\end{abstract}

Key-words: Photography; advertising; Kertesz; Outerbridge

\footnotetext{
* Profesor Titular del Departamento de Comunicación Audiovisual y Publicidad de la Universidad del País Vasco - Euskal Herriko Unibertsitatea, España. Recientemente ha publicado el libro Sombras de la fotografía que demuestra la artificiosidad de la fotografía Muerte de un miliciano de Robert Capa, así como otros iconos fotográficos relacionados con el siglo XX español. E-mail: josemanuel.susperregui@gmail.com.
} 


\section{Una aproximación a la fotografía publicitaria}

A pesar de las dificultades para la clasificación de las imágenes, más concretamente las fotografías, es cierto que algunas imágenes fotográficas están claramente definidas desde el comienzo de su existencia. Cualquier lector sabe perfectamente diferenciar una imagen de prensa de una imagen publicitaria, es decir, existen referencias icónicas suficientes para que esa distinción esté al alcance de cualquier lector, de manera que se puedan aplicar los códigos correspondientes bien se trate de una fotografía de prensa o de una fotografía publicitaria, por ejemplo. Esta relación directa con el tipo de lectura de una fotografía concreta significa la existencia de un paradigma también concreto, que equivale a un esquema formal que organiza los elementos visuales que componen una fotografía. La aportación de Jean-Marie Schaffer (2004, p.19) sobre la categorización de las fotografías resulta interesante cuando dice: "como seres humanos sólo tenemos acceso al mundo a través de las categorizaciones que recortan la realidad en un campo diferenciado y, por lo tanto, estructurado".

Entre las distintas categorizaciones hace especial hincapié en las funcionalidades atribuidas a las fotografías, que afectan al ámbito de la creación fotográfica. En otros términos, desde la realización o creación de una fotografía el autor utiliza una estrategia que considera la adecuada para el ámbito de recepción de la misma. Y es precisamente sobre esta estrategia que estructura la imagen, donde todavía persiste la discusión entre las fotografías del tenedor de André Kertesz y el cuello Idestyle de Paul Outerbridge, es decir, para saber cual de las dos imágenes conformó por primera vez el paradigma de la fotografía publicitaria moderna.

En el caso de la fotografía publicitaria para analizarla conviene diferenciar la imagen fotográfica propiamente dicha del conjunto del anuncio, compuesto por una imagen que acompaña a un texto y que se 
conjuntan a través del diseño gráfico. Es muy habitual que se analice la publicidad mezclando estos tres componentes principales, imagen, texto y diseño, por lo que el análisis de la fotografía publicitaria puede quedar afectado. Pero en este caso se trata de analizar la fotografía publicitaria tal cual se produce, tal y como el fotógrafo la ilumina y la compone en el visor, para que el análisis sea más concreto y quede libre de otras influencias. Otra referencia analítica interesante es la que hace G. Peninou (1976, p.21) sobre las dos formas publicitarias principales: de notoriedad o de marca. Atribuyendo a la primera forma un carácter denotativo, anclado en la reproducción y en la imitación, y apenas dando lugar a la creatividad y a la imaginación. En el otro extremo está la imagen de marca que se fundamenta en las connotaciones, en los atributos del objeto que provocan la imaginación a través de la manifestación de las connotaciones. La evolución de la fotografía publicitaria se fundamenta precisamente en la convivencia entre estas dos expresiones visuales, que comenzó reproduciendo el objeto publicitado para dar conocimiento de la existencia del mismo y evolucionó sumando la expresión de las connotaciones, para liberar la imaginación de los consumidores y provocar la mitificación del producto.

\section{De la notoriedad a la marca: la especificidad de la fotografía publicitaria}

Cuando se analiza la especificidad de la fotografía siempre se parte de la comparación con la pintura. Esta dependencia de la fotografía sobre la pintura tiene un fundamento cronológico en tanto que la experiencia pictórica es muy anterior a la fotografía, es una experiencia milenaria que sirvió de inspiración a los pioneros de la fotografía que sólo conocían la técnica y les quedaba por descubrir todo el potencial expresivo de la fotografía. Uno de los autores más interesantes en este análisis es Bazin (2004, p.26) cuando dice que: 
La fotografía, poniendo final al barroco, ha librado a las artes plásticas de su obsesión por la semejanza. Porque la pintura se esforzaba en vano en crear una ilusión y esa ilusión era suficiente en arte; mientras que la fotografía y el cine son invenciones que satisfacen muy definitivamente y en su esencia misma la obsesión del realismo.

Para este autor la aportación de la fotografía a la producción visual tiene un carácter psicológico debido a su perfección mecánica respecto del modelo, lo que en otras palabras se puede denominar el dibujo perfecto, a pesar de los precedentes como en el relato de Plinio (Libro XXXV) sobre la rivalidad de la perfección de las pinturas entre Ceuxis y Parasio, que lograron confundir sus creaciones con la propia realidad.

Pero la fotografía, además de sus relaciones con experiencias visuales anteriores, también tiene otras especificidades como indica Tisseron (2000, p.75): "Fotografiar es recorrer constantemente el camino de la percepción (el estado psíquico suturado por los sentidos en el que se encuentra el fotógrafo en el momento de la toma) a la representación (la imagen fotográfica que subsiste como único testimonio de dicho momento)."

Esta forma de entender la fotografía está más en función de la imagen instantánea propia de la fotografía de prensa, que requiere de una atención muy intensa para poder captar la imagen en el momento decisivo, en clara alusión a Henri Cartier Bresson. Pero en relación a la fotografía publicitaria resulta más interesante el concepto de Tisseron (2000, p.103) de la fotografía como envoltorio del mundo:

Cuando nos parece ver el mundo, lo único que vemos es su superficie opaca a la luz. Por ello, la mayor parte del mundo está condenada a mantenerse invisible para nosotros. Del mismo modo, la fotografía capta solamente la superficie opaca de los objetos. [...] Cuando creemos percibir el mundo, solamente percibimos la costra de las cosas; cuando creemos fotografiar el mundo, es tan solo esa costra lo que fotografiamos. 
Efectivamente, la fotografía publicitaria parte de la opacidad para plantear su estrategia visual y también para motivar su evolución. La fotografía publicitaria comenzó con unas composiciones con mucho objetos opacos colocados a modo de catálogo, que complicaban las composiciones, para ir reduciéndolos y ubicándolos en unos espacios uniformes o con unos fondos degradados que favorecen la presencia del objeto fotografiado, porque se establece una jerarquía visual entre la opacidad y la transparencia, ganando siempre la opacidad por su mayor interés visual, y cumpliéndose el reto de la fotografía publicitaria como contenedora del objeto anunciado.

La fotografía también está capacitada por su perfección visual para, una vez elegidos los objetos y los modelos de la representación, obtener una imagen que mantiene una unidad y una proporción natural entre los mismos, favoreciendo la credibilidad de la imagen representada, a pesar de su artificiosidad.

La fotografía publicitaria tiene una relación directa con la comunicación comercial para la venta de los productos industriales. Como consecuencia de la Primera Guerra Mundial se producen unos cambios políticos, sociales y económicos que afectan a los modos de vida; en el ámbito industrial estos cambios afectan a la organización del trabajo que persigue un aumento de la productividad para obtener una mayor competitividad así como una sociedad de consumo. La competitividad demanda una comunicación comercial cada vez mayor, desde finales del siglo XIX hasta la segunda década del siglo XX la comunicación comercial se quintuplica. Este modelo de comunicación también cambia sus estrategias ampliando el mercado hasta el ámbito nacional y recurriendo a nuevas estrategias donde la imagen tiene una presencia fundamental. La expansión de la radio y las revistas ilustradas contribuyeron al desarrollo de una cultura popular más uniforme, que se extendió a través de los medios de comunicación de masas. Como consecuencia de la industrialización y de la comunicación comercial, el mismo producto y la misma marca se podía comprar en cualquier lugar del país. La actividad industrial y mercantil se profesionalizó 
dinamizando la producción y comercialización de los productos, y ampliando la sociedad de consumo. Este desarrollo industrial también afectó positivamente a la demanda del arte comercial, porque se descubrió que la elegancia visual de la publicidad animaba al consumidor a adquirir los productos.

Hasta la segunda década del siglo XX las agencias de publicidad se dedicaban exclusivamente a la venta de espacios para los anuncios en los medios impresos. Con los cambios industriales y sociales tuvieron que aportar mayores servicios a los anunciantes a través de una mejor organización de las propias agencias. En Estados Unidos se fundaron algunas agencias importantes como J.Walter Thompson, Young and Rubicam y McCann Erikson, y en Francia se fundaron las agencias Dupuy, Printel, Synergie y Dorland Paris entre otras.

En el ámbito de la comunicación comercial el cambio que más ha marcado a la sociedad del siglo XX fue la sustitución del anuncio por la publicidad. La diferencia entre ambos medios reside en su estrategia, el anuncio es una comunicación textual mientras que la publicidad se basa en la fuerza de la emotividad de la imagen, especialmente de la imagen fotográfica. La importancia de la fotografía en la comunicación comercial fue valorada en 1929, en la revista francesa Le Professionel photographe, como indica Frizot (1994, p.560) en los siguientes términos:

La imagen fotográfica, en efecto, ha aportado un elemento nuevo. Lo mismo que si la ilustración es un lenguaje universal, la fotografía es la que permite presentar una reproducción fiel del artículo a vender y suple así de manera más elocuente que varias páginas descriptivas; su incorporación en la publicidad aumenta el valor del texto y contribuye a que esa publicidad quede durante más tiempo grabada en la memoria.

Esta valoración de la fotografía en la que la precisión, la fidelidad de la reproducción, es un factor fundamental coincide con la cultura de la mecánica, en clara sintonía con la concepción que se tenía en 
esta época de la propia fotografía como imagen mecánica. Esta valoración también es coincidente con la cultura clásica latina donde la imagen está siempre relacionada con la semejanza, a diferencia de la cultura de la Grecia clásica donde la imagen no está implicada con la fidelidad plástica.

Esta relación de la fotografía con la industria generó algunos cambios en la valoración de la propia fotografía y en su calidad artística. Anteriormente los pictorialistas entendían la fotografía como un trabajo de autor, que tenía un valor intrínseco fuera de todo interés comercial. Desde el comienzo, durante todo el siglo XIX, los profesionales de la fotografía estaban al servicio del arte por lo que sus motivaciones eran la obtención de buenas fotografías artísticas, donde quedaran reflejados los valores y los gustos de la época.

La fotografía publicitaria cambia esta forma de proceder porque los objetivos son otros. La fotografía de encargo, otra manera de denominar a la fotografía publicitaria, generó mucha actividad profesional pero comprometida con la comunicación comercial, es decir, la fotografía tenía que intermediar entre los fabricantes y los consumidores de manera comprensible y conmovedora. En esta modalidad de fotografía publicitaria la imagen no es un fin en sí mismo, donde la contemplación y la estética justifican la creación de la misma sino que, pasa también a ser un objeto de consumo al igual que cualquier otro producto industrial. El valor de la fotografía publicitaria no se mide por su nivel artístico convencional sino por su funcionalidad, es decir, por el resultado de la campaña publicitaria.

A su vez, la creatividad es un factor importante en la publicidad y más concretamente en la fotografía publicitaria, porque la innovación facilita la comunicación visual. La percepción de una imagen suele ser proporcional a su originalidad, sobre todo en aquellos ámbitos saturados donde las imágenes compiten entre sí. El factor creativo propio de la fotografía publicitaria fue un aliciente importante para atraer a esta actividad comercial a muchos artistas vanguardistas, sobre todo a aquellos fotógrafos interesados en la innovación permanente, es decir, en la creatividad. 
La fotografía quizá debido a la formación de imágenes automáticas a través del objetivo siempre ha tenido un alto nivel de experimentación, de inconformismo por parte del fotógrafo sobre lo que la cámara produce directamente. Este inconformismo y las ganas de experimentación atrajeron la atención de los artistas vanguardistas, sobre todo del constructivismo ruso y de la Bauhaus alemana, así como los artistas dadaístas y surrealistas.

La sociedad industrial de entre guerras recurrió a los artistas más vanguardistas, especialmente a los fotógrafos creativos para establecer los canales necesarios entre la oferta y la demanda, lo que a su vez supuso una serie de oportunidades desconocidas hasta entonces para la fotografía publicitaria. Al mismo tiempo, los artistas empezaron a valorar la importancia de la tecnología, como en la declaración que hizo el ruso Rodchenko a propósito de su teoría para el Primer Grupo de Constructivistas, como apunta Brik (2003, p.41): "La tecnología y la industria han hecho que el arte se enfrente al problema de la construcción no como una representación contemplativa, sino como una función activa."

La tecnología fotográfica puso al alcance de los artistas y fotógrafos unos recursos que ampliaron el expresionismo fotográfico. Los recursos ópticos de acercamiento y distorsión de imágenes, los encuadres informales, los montajes y los procesos químicos, principalmente, facilitaron la experimentación y la expresión fotográfica. La sociedad industrial también tuvo sus influencias en las nuevas estéticas por su intervención en el paisaje y por la presencia de los productos industriales en la sociedad moderna. Uno de los artistas que mejor compendia este periodo de experimentación es el húngaro Laszlo Moholy-Nagy para quien la experimentación no estaba condicionada ni por los contenidos ni por los soportes, como indica Rosemblum (1981, p.437): "Ignoró las distinciones tradicionales entre la expresión gráfica y la fotográfica, entre el arte como expresión personal y el arte como utilidad, y entre la práctica y la teoría para trabajar creativamente en todos los estilos y medios que escogiera". 
En estos primeros años de vida de la fotografía publicitaria las diferencias entre Europa y Estados Unidos eran notables porque los puntos de partida también diferían. En Europa los fotógrafos eran más independientes y más experimentales, es decir, más preocupados por las relaciones formales de sus imágenes, mientras que en Estados Unidos los fotógrafos estaban más condicionados por el propio sistema industrial que, a través, de las agencias de publicidad ejercían un mayor control sobre los fotógrafos. Siempre se ha relacionado la fotografía publicitaria americana con la reality photo, es decir, con una imagen que describe la realidad tal cual, al estilo de la fotografía de Paul Strand The Akeley Camera (1923) o en el caso de otros fotógrafos como, por ejemplo, Edward Weston que en la década de los años 20 produjo fotografías artísticas muy interesantes en la línea de la reality photo, tales como el retrete, las conchas y los pimientos.

La relación cultural de la fotografía publicitaria y los condicionamientos de la misma quedan bien definidos por Giselè Freund (1976, p.7) cuando dice: "Cada sociedad produce unas formas definidas de expresión artística que, en gran medida, nacen de sus exigencias y de sus tradiciones, reflejándolas a su vez. Toda variación en la estructura social influye tanto sobre el tema como sobre las modalidades de la expresión artística."

Al cabo de los años el paradigma de la fotografía publicitaria es una imagen de marca, descriptiva, subordinada, estereotipada, pero con un margen de creatividad suficiente para diferenciarse de otros mensajes publicitarios debido a la alta competencia publicitaria, que exige la aplicación de nuevas fórmulas que el fotógrafo debe resolver para que la comunicación visual logre sus objetivos. El paradigma de la fotografía publicitaria es el resultado de un esquema que sigue unas pautas de comportamiento, como describe Walter Nurnberg (1940, p.18):

Un fotógrafo de publicidad tiene que traducir una idea dada en una forma concreta, idea que ha sido formada en la imaginación del director artístico, y el grado en el cual el fotógrafo ha 
conseguido traducir la idea, interpretarla, y seguir fielmente su imaginación, por supuesto, determina el rol preciso del fotógrafo para conjuntar la actividad con la imagen finalizada.

A pesar de este proceso tan lineal y concreto, el fotógrafo publicitario tiene un margen de actuación importante para su creatividad, de manera que las ideas del director artístico adquieran unas formas concretas y coherentes con el mensaje publicitario. El propio Walter Nurnberg, conocido fotógrafo publicitario y autor del libro Lighting for Photography: Means and Methods, define la fotografía publicitaria como una expresión artística relacionada con el contenido del mensaje publicitario, pero teniendo en cuenta que la experiencia emocional que puede causar una fotografía publicitaria no debe ser romántica sino realista, una emoción ligada al objeto que se anuncia. Tampoco se puede confundir la expresión fotográfica con la explicación lógica del objeto, porque esta expresión busca despertar los impulsos del deseo desde la influencia artística. El reto del fotógrafo publicitario consiste en desarrollar una idea previa para lograr una imagen que se ajuste al concepto del director artístico y al gusto del cliente, recurriendo a los valores estéticos del producto que se anuncia para potenciar su valor en el mercado.

\section{La fotografía publicitaria como fotografía formal: los ejemplos de Kertész y Outerbridge}

En la adaptación de la fotografía a las necesidades de la comunicación publicitaria se produjo una evolución, cuyo punto de partida era la fotografía documental, es decir, la mera denotación del producto que se anunciaba hasta formular el paradigma de la fotografía publicitaria que incluye unas connotaciones que configuran esta 
categoría visual. La disputa sobre la formulación de este paradigma se establece entre dos fotógrafos: el húngaro André Kertész y el americano Paul Outerbridge; el primero con su conocida fotografía del tenedor y el segundo con su cuello de camisa.

La obra fotográfica de André Kertész está relacionada más con la fotografía artística que con la publicidad, y siempre alejado de las tendencias de la época. Durante su experiencia parisina sus amigos le propusieron la estética francesa de comienzos del siglo XX como punto de partida, más concretamente el estilo cubista y el surrealista. Kertész se mantuvo alejado de estos ambientes para reafirmarse en su independencia y en su singularidad. Según Borhan (1994, p.22), Kertész, entendía la modernidad de la siguiente manera: "La modernidad para él está en la visión, no está en la mecánica ni en la industria en pleno esplendor, ni en las intervenciones plásticas ni en las operaciones de laboratorio."

Esta forma de entender la modernidad no le impidió publicar ocasionalmente en revistas comprometidas con el surrealismo, como el Minotauro de André Breton. Estas colaboraciones esporádicas no significaron una afinidad con este movimiento artístico ni con ningún otro, porque no se ajustaban al compromiso que mantenía con lo que denominaba "naturalismo". A excepción de algunas experimentaciones de imágenes deformadas que publicó en la revista $V u$, su concepto fotográfico no requería de técnicas para la manipulación de la imagen. Cuando una fotografía de Kertész evoca el surrealismo no es por una intencionalidad o búsqueda concreta del artista, sino por la mera observación de la vida diaria que también produce escenas que parecen recreaciones surrealistas, cuando en realidad son encuentros naturales del fotógrafo con escenas cotidianas.

Se le puede considerar como opuesto a los principios de los movimientos fotográficos europeos, como la Nueva Objetividad de Alemania junto a la Bauhaus, así como la Nouvelle Photographie francesa que subliman los objetos industriales y la serialización de los mismos. Kertész, sin embargo, fotografía los objetos manufacturados 
y usados como en la composición de Les Lunettes et la Pipe de Mondrian (1926), porque considera que esos objetos son la metáfora de su propietario, los símbolos que le representan. En sus composiciones no recurre a la geometría como hacen los fotógrafos de la Nueva Objetividad, emplea fórmulas más clásicas, más pictóricas, donde las connotaciones están en la contextualización de la composición. La fenomenología fotográfica de Kertész se puede definir con una palabra: descripción. Este fotógrafo no concibe sus imágenes fotográficas si no están conectadas a la vida, si no pertenecen a alguien, y esta personalización le diferencia de otros fotógrafos contemporáneos así como de la propia fotografía publicitaria, que tratan de atraer la mirada del lector o espectador enfatizando la belleza de los productos industriales impersonales.

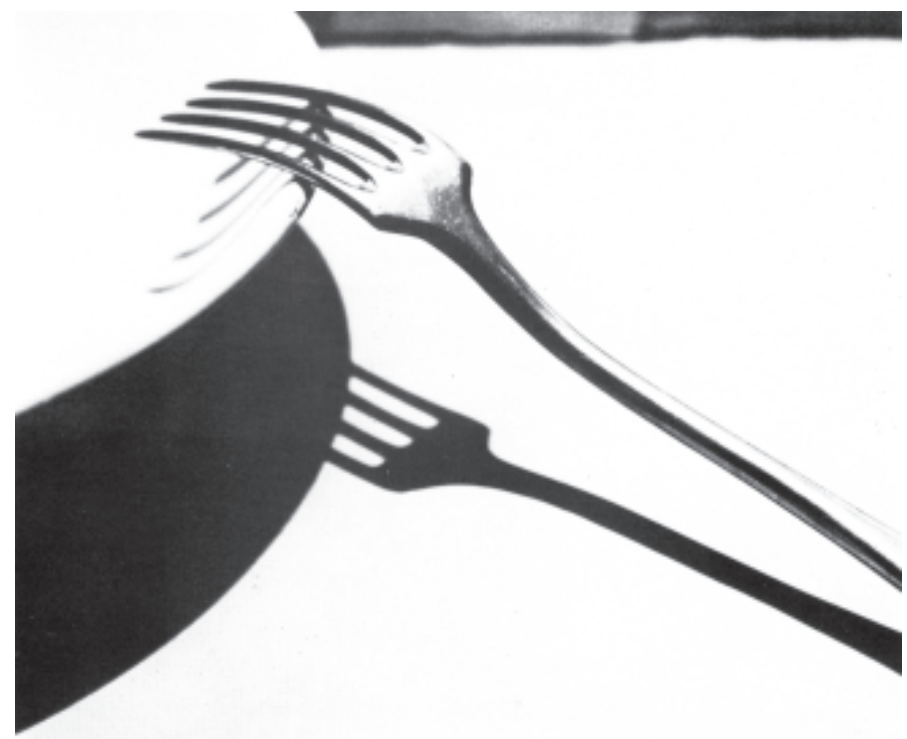

Figura 1 - Tenedor

Fotografia: André Kertesz. 1928

Fuente: Renate y L. Fritz Gruber (1982) 
La fotografía del Tenedor (1928) es una composición formada por un tenedor y una parte de un plato donde se apoya el cubierto. Es una fotografía de bastante contraste donde las sombras duplican las formas de los dos objetos de la composición que, a su vez, están perfectamente perfilados. Lo que más llama la atención de esta fotografía es su naturalidad, parece que alguien ha colocado el tenedor sobre el plato y se ha marchado, todo ello envuelto en un ambiente austero. En realidad no se trata de una fotografía publicitaria tal y como lo hemos expresado anteriormente, Kertész compró un tenedor cualquiera en el bazar del Hotel de Ville de París para hacer la composición. Con esta fotografía participó en varias exposiciones, en el Salon de l'Escalier de París (1928), y en este mismo año también se expuso en la galería L'Epoque de Bruselas y en el Salon International de Rótterdam. Al año siguiente se celebró en Sttugart la exposición internacional Film und Foto, donde expusieron las fotografías de Lazlo Moholy-Nagy, Anneliese Kretschmer, Eugène Atget, Ralph Steiner, Alexander Rodtschenko, Paul Outerbridge y el propio Kertész que volvió a exponer el Tenedor además de otras fotografías.

Entre los organizadores de la exposición Film und Foto se encontraba un fabricante de cubiertos, Peter Bruchmann, interesado en la fotografía de Kertész para utilizarla en un anuncio de sus cubiertos. Kertész puso una condición para la utilización de su fotografía como imagen publicitaria, que fuera reconocida como una expresión estética.

Como se ha podido comprobar esta fotografía de Kertész, el Tenedor, es un ejemplo raro de fotografía publicitaria porque estaba concebida como un fin en sí misma y justificada por la contemplación y la estética. Mientras que la fotografía publicitaria como hemos apuntado anteriormente es una imagen funcional puesta al servicio de un producto industrial, que a su vez se convierte en un objeto más de consumo. En estas condiciones difícilmente se puede considerar a la fotografía el Tenedor de André Kertész como paradigma de la fotografía 
publicitaria, más bien es un búsqueda personal del artista que, ocasionalmente, documenta una comunicación publicitaria.

La carrera profesional de André Kertesz discurrió como ilustrador de algunas de las revistas más importantes de la época. A pesar de su concepción de la fotografía como un medio de comunicación directamente ligado a la vida, lo que le impedía mantener unas relaciones fluidas con los editores de las revistas ilustradas, acabó aceptando algunos trabajos para House and Garden, Vogue, Town and Country. En 1946 firmó un contrato en exclusiva durante 15 años con Alexander Liberman, director de la revista House and Garden, que supuso un cambio sustancial en su actitud profesional porque acabó aceptando una línea editorial que trastocaba su libertad fotográfica. Por primera vez en su carrera profesional, se limita a la ilustración fotográfica aceptando unas condiciones previas y unos temas concretos como jardines, interiores, mobiliario y objetos decorativos. Por lo tanto, la relación de André Kertesz con la fotografía publicitaria fue casual porque su carrera profesional discurrió motivada por sus inquietudes artísticas y también por los encargos de las revistas ilustradas.

A diferencia de Kertész, la obra fotográfica del americano Paul Outerbridge está más relacionada con la publicidad, lo que no significa que su obra sea meramente comercial. Paul Outerbridge fue un fotógrafo moderno cuyas inquietudes artísticas supo aplicarlas a los encargos que recibía bien de las revistas ilustradas o bien directamente de las agencias de publicidad, como resume en pocas palabras Raúl Eguiazabal (2001, p.146) cuando dice: "un autor que, sin moverse de la fotografía publicitaria, hizo posible una síntesis entre la objetividad y el surrealismo".

Sobre el arte en general y la fotografía en particular pensaba que se podían lograr unas imágenes autosuficientes de manera que sus formas artísticas podían explicarse por ellas mismas, sin tener que recurrir a los textos explicativos como suele ser habitual en la fotografía con los pies de foto. Outerbridge era un fotógrafo que pensaba en clave artística, es decir, su objetivo era crear obras de arte a través de la técnica fotográfica 
como queda bien patente en su definición del arte: "El arte es la vida vista a través del deseo de perfección y de belleza del hombre, una huida hacia delante de las realidades sórdidas de la vida en un mundo creado por su imaginación”. (OUTERBRIDGE, 1952, p.54).

Su formación se puede resumir con su paso por la Clarence White School of Photography, sus relaciones con los fotógrafos vanguardistas Alfred Stieglitz, Paul Strand y Edward Weston entre otros, así como sus estancias en París y Berlín, ciudades que acogían a los movimientos artísticos más vanguardistas en los primeros años del siglo XX y donde hizo amistad con algunos de los artistas más relevantes como Marcel Duchamp, Man Ray, Picabia, Brancusi, Archipenko y Ernst. Fue en París donde construyó el mayor estudio de fotografía, equipado con la mejor tecnología para potenciar su creatividad. La inauguración del estudio creó una gran expectación entre los asistentes, sobre todo cuando Outerbridge presentó la primera fotografía producida en su nuevo estudio. Se trataba de la fotografía de un huevo, anécdota que resume en parte la personalidad de este fotógrafo y define también sus inquietudes formales según Agha (1999, p.182):

Outerbridge raramente ha fotografiado un objeto directamente a partir de su aspecto natural, como lo hace Ansel Adams. Outerbridge no estaba seducido por las apariencias superficiales; se interesaba sobre todo en la búsqueda de los principios formales no aparentes en la belleza interior de una composición. Efectuaba numerosos estudios con el fin de traducir la belleza existente en los objetos más simples y más humildes.

La fotografía que mayor trascendencia tuvo entre sus creaciones publicitarias fue el cuello Ide Collar, fotografía que fue publicada por primera vez en la revista americana Vanity Fair, en noviembre de 1922. Se trata de un cuello de camisa almidonado de la marca Idestyle, colocado sobre un tablero de ajedrez. La aportación más importante que hace Outerbridge con esta composición es la transformación de un objeto cotidiano como es un cuello de camisa en un objeto excepcional, a través de la composición y la iluminación principalmente. Es una 
composición cubista, formada por las figuras geométricas propias de un tablero de ajedrez, en contraste con las líneas curvas de un cuello de camisa, donde la iluminación modula los volúmenes del cuello de camisa con la gradación de la luz que produce una zona luminosa donde se puede leer: IDESTYLE 14 3/4 UNOCORD BUTTONMOLES T464, que es el centro de interés de esta imagen comercial. Imagen o fotografía comercial que llamó la atención del vanguardista Marcel Duchamp que consideró esta composición de Outerbridge como un objet-trouvé, por ese encuentro aparentemente casual entre un cuello de camisa almidonado y un tablero de ajedrez, siguiendo las pautas de la metáfora surrealista más conocida: Tan hermoso como el encuentro entre un paraguas y una máquina de escribir sobre la mesa de un quirófano. Metáfora que se podía aplicar a la composición de Paul Outerbridge en los siguientes términos: Tan hermoso como un cuello de camisa sobre un tablero de ajedrez. Este encuentro del cuello de camisa con el tablero de ajedrez tiene, en principio, un marcado carácter surrealista que ha conformado un estereotipo muy recurrido en la fotografía publicitaria moderna, y que es el fundamento de muchas composiciones publicitarias que se inspiran en este tipo de asociaciones formales para aportar imágenes originales. El surrealismo supone todavía para la fotografía publicitaria una fuente inagotable de inspiración.

Con la fotografía del cuello Idestyle, Outerbridge cumple con los objetivos tanto comerciales como artísticos, porque no se trata de un cuello de camisa cualquiera sino de uno concreto, por lo que el espíritu comercial de esta fotografía está presente, así como el artístico por la clave surrealista que envuelve a esta composición fotográfica generando una emoción estética que provoca un deseo, como lo manifiesta Yochelson (1983, p.28):

La elegante curva y sutil modelado del cuello sugiere la elegancia del que lo lleva puesto. El enfoque nítido permite la lectura del nombre de la marca en el interior del cuello así como la talla delgada, 143/4, del imaginario propietario. En un instante convergen la información necesaria y la tentación de compra. 


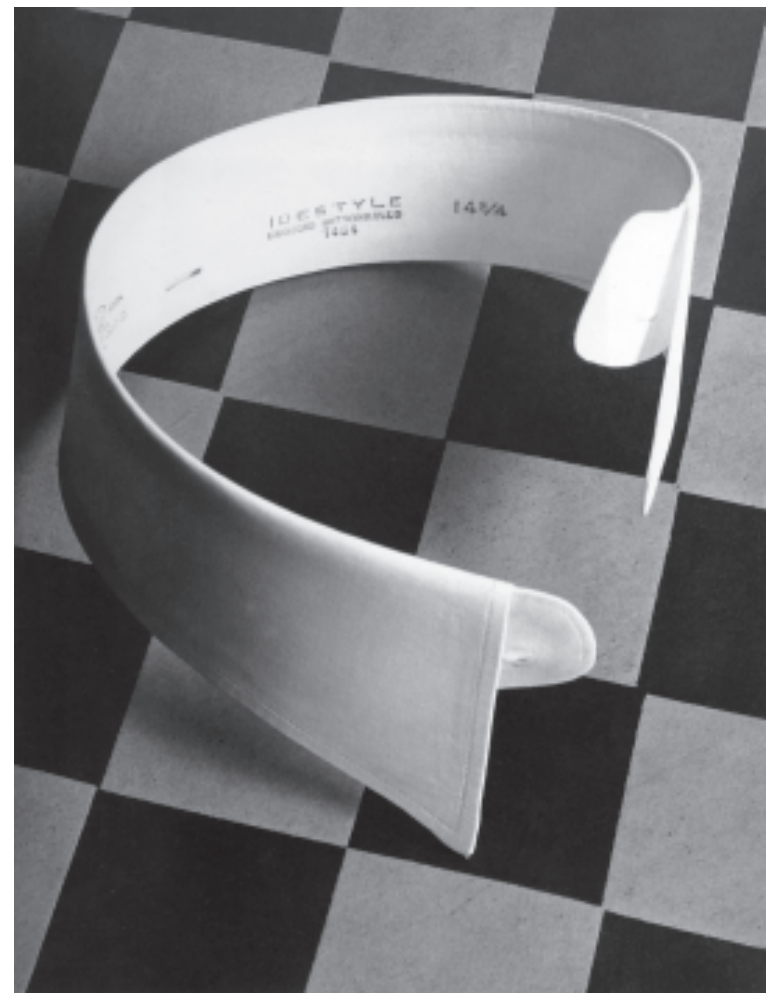

Figura 2 - Cuello Idestyle

Fotografia: Paul Outerbridge. 1922

Fuente: Dines-Cox Elaine y Carol McCuster (1999)

Como una de sus mayores preocupaciones artísticas era la búsqueda de la belleza existente en los objetos cotidianos, Outerbridge se aplicó en la técnica del preciosismo, en contraposición con elflou o desenfoque tan recurrido por otros estilos fotográficos como el pictorialismo. La técnica del preciosismo busca la nitidez de la imagen, el detalle que define visualmente el objeto de la composición y que resulta tan idónea en la aplicación de la fotografía publicitaria, donde la visualización óptima del objeto en todos sus detalles es la máxima prioridad de la comunicación comercial. Esta visualización óptima requiere del dominio de la técnica fotográfica, de la utilización de la 
cámara de estudio porque su aplicación garantiza simultáneamente una composición enfocada en toda su superficie y también una gran definición de la imagen. Tanto el enfoque como la definición resultan imprescindibles en la comunicación comercial para transmitir la mejor información que se publicita, incluyendo los textos impresos en los productos.

\section{Consideraciones finales}

La sustitución de las ilustraciones por las fotografías en la actividad publicitaria manifiesta claramente la mayor idoneidad de la técnica fotográfica para la comunicación comercial, generando una imagen específica que no entra en conflicto en cuanto a sus formas y contenidos con otro tipo de fotografías, como sucede en la prensa donde cualquier lector diferencia perfectamente una fotografía comercial de otra de información gráfica. Esta distinción se debe a la existencia de paradigmas tanto en la prensa gráfica como en la fotografía publicitaria, que no sólo se distinguen por los contenidos sino más bien por las distintas estrategias empleadas en ambos casos. Si la fotografía de prensa es espontánea, donde el fotógrafo solamente controla el acto fotográfico pero no la realidad, en la fotografía publicitaria forma parte del equipo que desarrolla el proyecto de comunicación comercial. El fotógrafo publicitario es el intérprete de la idea original del director artístico y, también, el artífice de su realización cuya única limitación será su propia capacidad y la conformidad del anunciante, para generar en el receptor una experiencia emocional que esté ligada al producto que se anuncia.

Si comparamos las fotografías de André Kertesz y Paul Outerbridge, el Tenedor y el Cuello Idestyle, en cuanto a su realización la diferencia más notable es que la fotografía de Kertesz en origen no es un proyecto de comunicación comercial, es una experiencia de 
búsqueda personal propia de un artista fotógrafo que la presenta al público por primera vez en una sala de exposiciones, donde un fabricante se interesa para anunciar sus cubiertos. Esta propuesta crea un conflicto en André Kertesz que al principio no acepta la propuesta del fabricante hasta que se compromete a respetar su expresión artística. Esta forma de proceder en la comunicación comercial de los cubiertos de Peter Bruchmann adolece de un error fundamental, en la fotografía no se muestra la marca del producto, no se identifica a un fabricante concreto sino una categoría de producto. La composición de la fotografía tampoco tiene una orientación específica sino genérica, la presencia visual del tenedor se desdobla con su sombra, creando una simetría de formas que afecta a su observación. La realización técnica también tiene otro error porque el extremo izquierdo del tenedor queda desenfocado, precisamente su parte más funcional es la que presenta menos información sobre el producto que se anuncia.

La trayectoria profesional de André Kertesz queda alejada de algunos movimientos fotográficos que tenían presente la publicidad como contenido de sus composiciones. La Nueva Objetividad, el Bauhaus o la Nouvelle Photographie enfocaron sus cámaras a los objetos industriales para descubrir la estética de una sociedad industrial que desencadenó la sociedad de consumo. A Kertesz más que la producción industrial le interesaron los productos manufacturados como Les Lunettes et la Pipe de Mondrian.

La fotografía de Paul Outerbridge, Idestyle Collar o Ide Shirt Collar, si tiene una relación directa con la fotografía publicitaria. Se trata de una composición paradigmática que fue realizada durante su estancia en la mítica escuela Clare White School of Photography, y aunque se trata de una obra de juventud es la más conocida de su obra artística. Esta composición reúne todas las condiciones de una fotografía publicitaria porque Outerbridge recibió el encargo del fabricante de cuellos de camisa Ide para comercializar su producción. La interpretación que hace de la idea original del fabricante está 
enfocada a la elegancia como valor añadido por la elección y compra de este cuello de camisa Idestyle.

La composición está resuelta estableciendo un claro contraste entre las formas orgánicas del cuello de camisa y las formas geométricas del tablero de ajedrez. Con estos dos elementos también establece una relación directa entre elegancia y nivel cultural, generando una experiencia emocional que, como decía Walter Nurnberg, está ligada al objeto que se anuncia. La imagen del cuello es una imagen retórica, una sinécdoque que nos invita a imaginarnos, como dice Yochelson: "la elegancia del que lo lleva puesto".

Pero está composición no está sujeta a la lógica porque sobre un tablero de ajedrez lo que se colocan son las fichas y no un cuello de camisa. Esta falta de lógica en la relación de los elementos de la composición fotográfica es una de las mayores aportaciones de Paul Outerbridge a la fotografía publicitaria, porque inicia un itinerario nuevo para superar la imagen de notoriedad de la primera etapa de la fotografía comercial. Esta fotografía está resuelta como una obra surrealista y llamó la atención del propio Marcel Duchamp que recortó la ilustración de la revista Vanity Fair, para clavarla en su estudio porque era un objet-trouvé que invitaba a la redefinición del arte.

La técnica utilizada en la producción de esta fotografía también es paradigmática porque se aproxima a la imagen perfecta. Toda la composición está perfectamente enfocada y la atención del lector está controlada por la iluminación. Es decir, el fotógrafo ha establecido un itinerario para nuestra atención visual, que se inicia desde la zona más iluminada para descender hacia las sombras. Con mucha sutileza Paul Outerbridge iluminó la composición de manera que nuestra atención se dirija en primer lugar a la etiqueta, donde está la información del producto que es la clave para el éxito comercial. Podemos leer la marca, las características y su talla. Por lo tanto, como conclusión principal, podemos afirmar que la fotografía de Paul Outerbridge es el paradigma de la fotografía publicitaria y no el Tenedor de Kertesz, 
porque el Cuello Idestyle es el referente, según la estimación de G. Peninou sobre la fotografía publicitaria, como la imagen de marca que se fundamenta en los atributos y en la manifestación de las connotaciones que provocan la imaginación del lector.

\section{Bibliografía}

AGHA, M. F. Paul Outerbridge. Köln: Taschen, 1999.

BAZIN, André.¿Qué es el cine? 6.ed. Madrid: Rialp, 2004.

BORHAN, Pierre. André Kertész: la Biographie d'une oeuvre. París: Sueil, 1994.

BRIK, Osip. Alexander Rodchenko. Bilbao: Fundación Bilbao Bizkaia Kutxa, 2003.

DINES-COX, Elaine; McCUSKER, Carol. Paul Outerbridge. Köln: Taschen, 1999.

EGUIAZABAL, Raúl. Fotografía publicitaria. Madrid:

Cátedra, 2001.

FREUND, Giselè. La fotografía como documento social. Barcelona: Gustavo Gili, 1976.

FRIZOT, Michel. Nouvelle histoire de la photographie. París: Bordas, 1994.

GRUBER, Renate; FRITZ, L. EI museo ideal de la fotografía.

140 años de obras maestras de la Fotografía. Barcelona:

Gustavo Gili, 1982. 
NURNBERG, Walter. The science and technique of advertising. London: The Studio Publications, 1940.

PENINOU, G. Semiótica de la publicidad. Barcelona: Gustavo Gili, 1976.

ROSEMBLUM Naomi. A world history of photography. New York: Abbeville Press Publishers, 1981.

SCHAFFER, Jean-Marie. La fotografía entre visión e imagen: la confusión de los géneros en fotografía. Barcelona: Gustavo Gili, 2004.

TISSERON, Serge. EI misterio de la cámara lúcida: fotografía e inconsciente. Salamanca: Universidad de Salamanca, 2000.

YOCHELSON, Bonnie. Clarence H. White reconsidered: an alternative to the modernist Aesthetic of Straight Photography. Studies in Visual Communication, Iowa, v.9, p.25-44, 1983. 